\title{
The importance of monitoring renewable energy plants: three case histories
}

\author{
Renato Lazzarin ${ }^{1, *}$ \\ ${ }^{1}$ DTG, University of Padova, 36100 Vicenza, Italy
}

\begin{abstract}
Many renwable energy plants are put into operation without providing a monitoring system to evaluate their performance over time. Then if is often difficult to realise the bad working of the system and the loss of efficiency results in an economic loss. Three quite different examples are reported to illustrate how real performance can be lower than designed due respectively: 1 . To bad settings of the parameters; 2 . To a hurried commissioning that did not reveal the mistakes in the design of the plant; 3 . To a failure of a single component over time.
\end{abstract}

\section{Introduction}

Renewable energy plants are seldom simple plants except small installations such as DHW solar plants or small photovoltaic plants. They often include the renewable section and conventional auxiliaries, usually boilers. Hot and/or cold storage is usually present and a suitable control system governs the plant. The plant manager is frequently another person than the designer and he does not always possess a comprehensive understanding of the system control logic.

Many renewable energy plants are put into operation without providing a monitoring system to evaluate their performance over time. It happens that seasonal performance may be well below the values recorded during commissioning or planned in the design. Or wrong setting of parameters or the failure of some components prejudices system performance: the system goes on operating but at a lower efficiency than designed. In the absence of a supervision it is difficult to realise the bad working of the system. In fact the auxiliary provides the service and it is not straightforward to decide whether the energy bill, that often covers a whole month or more different needs than the considered plant, is appropriate. The loss of efficiency results in an economic loss that might go on for years, losing the waited advantages of a more expensive, but potentially also more efficient installation.

Three quite different examples are reported to illustrate how real performance can be lower than designed due respectively:

1. To bad settings of the parameters;

\footnotetext{
*Corresponding author: renato@gest.unipd.it
} 
2. To a hurried commissioning that did not reveal the mistakes in the design of the plant;

3. To a failure of a single component over time.

\section{The first example: a motor driven heat pump HVAC plant}

The "San Nicola" building, in the historic heart of the town of Vicenza, has been hosting since 1999 the Department of Management and Engineering of the University of Padova (DTG). The building has a net floor area of about $4,200 \mathrm{~m}^{2}$, and a volume of $14,300 \mathrm{~m}^{3}$.

The building HVAC system consists of:

- Two pipes fan-coil heating and cooling system.

- Ventilation and air conditioning system $\left(21,700 \mathrm{~m}^{3} / \mathrm{h}\right.$ AHU for humidity control and supply of outdoor air). The AHU is made of a cross flow heat exchanger, the preheating section, the cooling/dehumidification section, the post heating section.

- Extraction system, for exhaust air from the toilets.

The heating and cooling production is obtained through a gas engine driven heat pump and two condensing boilers.

The air to water heat pump can operate both in heating and cooling mode by means of a four-way inversion valve, and it is driven by a gas reciprocating engine. It is possible to modulate the heating/cooling capacity in a continuous way by varying the engine speed from 1800 to $2600 \mathrm{rpm}$, acting on the throttle butterfly valve. A further modulation down to $40 \%$ of the rated heating/cooling power is obtained through the inlet valve unloader on the compressor cylinders. The rated cooling capacity is $276 \mathrm{~kW}$ with a gas consumption of $22 \mathrm{Nm}^{3} / \mathrm{h}$, while the rated heating capacity is $380 \mathrm{~kW}$ with a gas consumption of $19 \mathrm{Nm}^{3} / \mathrm{h}$ (respectively in summer for $35^{\circ} \mathrm{C}$ outdoor air and evaporator inlet/outlet $12 / 7^{\circ} \mathrm{C}$, and in winter for $10{ }^{\circ} \mathrm{C}$ outdoor air and condenser inlet/outlet $40 / 45^{\circ} \mathrm{C}$ ).

Heat recovery from the engine is provided from the lubricant oil, the cooling water and the exhaust gases, as to achieve a rated recovery of $126 \mathrm{~kW}$ when working in cooling mode and $109 \mathrm{~kW}$ when in heating mode, available at about $70^{\circ} \mathrm{C}$. The EER in refrigeration mode is 4.5, with a PER (Primary Energy Ratio, i.e. the ratio of the cooling/heating capacity over the fuel consumption in terms of primary energy) of 1.4; in heating mode the COP is quite high (over 5) with a PER of 1.5.

The whole machine (heat pump and engine) is then equipped with a double hydraulic circuit: the heat pump one, providing chilled water $\left(7 / 12^{\circ} \mathrm{C}\right)$ in summer and warm water $\left(45 / 40^{\circ} \mathrm{C}\right)$ in winter, and the engine heat recovery system, from now on called the high temperature circuit, providing hot water $\left(70 / 65^{\circ} \mathrm{C}\right)$. The control is given by a digital display controller that drives the engine speed control and the inlet valve unloader of the cylinders. The system has two inertial storages, 30001 on the heat pump circuit and 15001 on the heat recovery circuit, to let the heat pump working on the smoothest possible load profile. Two condensing boilers of $285 \mathrm{~kW}$ are installed to supplement the heat pump.

During wintertime the fan-coils are served by the heat pump circuit $\left(45^{\circ} \mathrm{C}\right)$, while the pre and post heating coils of the AHU are served by the high temperature circuit $\left(70^{\circ} \mathrm{C}\right)$. The two condensing boilers $\mathrm{C} 1$ and $\mathrm{C} 2$ are activated as integration of the heat pump (or as backup in case of heat pump failure) on two different thresholds of the distribution return temperature of the heat pump circuit (fan coils); $\mathrm{C} 2$ can also be activated to integrate the high temperature circuit, based on a temperature threshold of the heat recovery inertial storage (Fig. 1). 


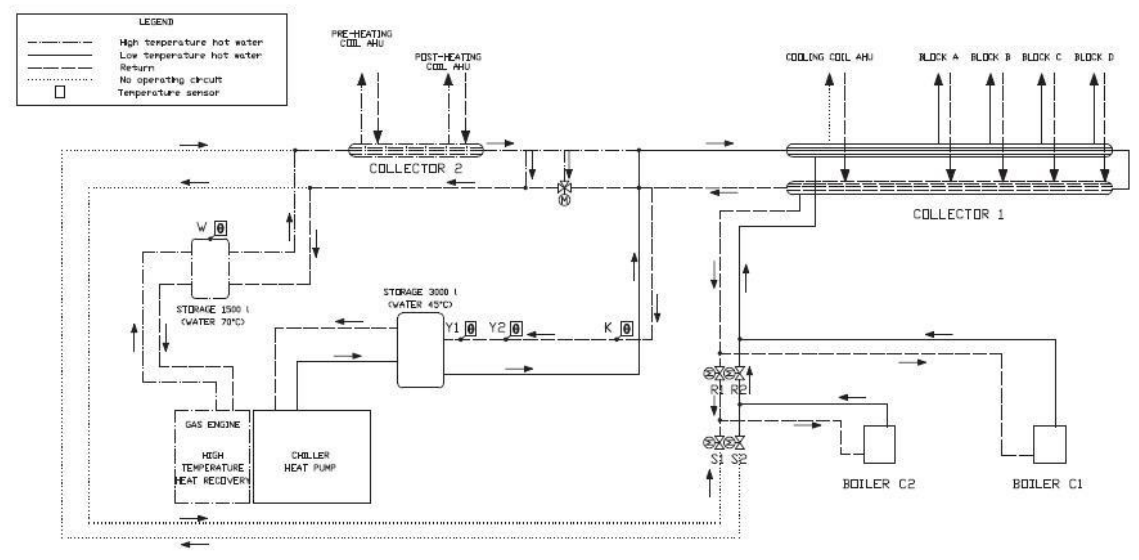

Fig. 1. HVAC plant winter operating diagram.

An analysis of the first year of operation revealed some malfunctions of the plant due to mistakes in the commissioning phase and to lack of a correct maintenance and operation of the system and suggested that the plant had a low efficiency. In fact heating was mainly provided by the boilers, which were set to produce water at $75^{\circ} \mathrm{C}$ because of a bad control and of a missing temperature sensor, so they were not running in condensing mode. The heat pump was working mainly with on-off cycles instead of part load operation, with a consequent de-rating in terms of COP, increased thermo-mechanical stresses on the engine and a poor use of the heat recovery. Owing to errors in the control strategy presented above, this resulted in a continual use of boiler $\mathrm{C} 2$ and incidental use of the heat pump (some minutes per hour). This was due to a mistake in the wiring of the valves' drives and led to relevant energy losses in the first year of operation. Finally, small troubles (arisen from calibration errors on several temperature controllers) did not allow the correct operation according to the design control strategy previously described.

Some test days were recorded by monitoring the natural gas consumption and the outdoor temperature, to obtain the gas consumption in terms of $\mathrm{Nm}^{3}$ per "degree-hour" (dh) to evaluate the different performance of the heat pump and the condensing boilers in winter heating. Three test days were recorded in the design operating mode (heat pump priority) and three test days were recorded running only the condensing boilers. The results are summarised in Table 1. Condensing boiler mode leads to a consumption exceeding over $50 \%$ that of the design operating mode, highlighting the great efficiency of the engine heat pump system. The consumption expressed as $\mathrm{Nm}^{3}$ per $\mathrm{dh}$ was used to evaluate the annual consumption by means of the dh data for the town of Vicenza (around 28,000, from 15th October to 15th April). The annual heating average cost passed from 15,059 $€$ in design operating mode to $21,830 €$ with condensing boilers.

Table 1. Comparison between the natural gas consumption per dh in design operating mode and in condensing boiler mode (averaged on the three days of each test run).

\begin{tabular}{|c|c|c|c|}
\hline Mode & $\begin{array}{c}\text { Gas consumption } \\
\text { in the test run } \\
{\left[\mathbf{N m}^{3}\right]}\end{array}$ & $\begin{array}{c}\text { Degree } \\
\text { hours }[\mathbf{d h}]\end{array}$ & $\begin{array}{c}\text { Consumption } \\
\text { per degree-hour } \\
{\left[\mathbf{N m}^{\mathbf{3}} / \mathbf{d h}\right]}\end{array}$ \\
\hline $\begin{array}{c}\text { Design operation } \\
\text { (HP + condensing boiler) }\end{array}$ & 70.10 & 91.1 & 0.77 \\
\hline Condensing boilers & 87.40 & 77.0 & 1.14 \\
\hline
\end{tabular}




\section{The second example: ground water heat pump for a historical building}

The Basilica Palladiana is a historic building, designed by Andrea Palladio in the $16^{\text {th }}$ century, sited in one of the most famous square in the centre of Vicenza. It was deeply retrofitted between 2007 and 2012 to make it a cultural centre for the city. The new HVAC plant is an open loop water source heat pump system using underground water as heat source or as heat sink. Two wells were built (distance about $50 \mathrm{~m}$ ) to produce and inject the water from the layer (40 $\mathrm{m}$ deep).

The use of underground water in heat pump plants is strictly regulated (and till 2015 forbidden) in the territory of Vicenza for environmental reasons. So the realization of the plant here described was allowed by local Authority to have a benchmark for the use of underground water for air conditioning uses. For such reasons the installation of a data logging system was prescribed in order to evaluate the energy and environmental performance of the HVAC plant. The underground water is available at $14^{\circ} \mathrm{C}$ and used as heat pump source (during heating season to supply hot water at $45-40^{\circ} \mathrm{C}$ ) or as chiller heat sink (during cooling season to supply cold water at $7-12^{\circ} \mathrm{C}$ ). The project provides three main circuits (Fig. 2) :

- underground water layer circuit: it is an open loop with the pumps to circulate the well water (two pumps, one backup, $18 \mathrm{~kW}$ nominal power at $70 \mathrm{~m}$ water column head each, controlled by inverter). Sand filters are enclosed as well. This circuit exchanges heat with primary circuit by means of two stainless steel heat exchangers (one backup), $700 \mathrm{~kW}$ nominal power each. The control logic is set up to operate (by an inverter) the production well pump as a function of a set point of the condensation/evaporation water circuit;

- primary circuit: it allows the heat exchange between the underground water and the water of the evaporator/condenser circuit of the heat pump/chiller avoiding the direct use of the underground water. This is done by two pumps (cooling pump in Fig. 2, one backup, constant flow rate $-90 \mathrm{~m}^{3} \mathrm{~h}^{-1}-, 5 \mathrm{~kW}$ power, $12 \mathrm{~m}$ head). The heat pump/chiller is an electrical water/water one, six scroll compressors set up in two parallel circuits, R410A as refrigerant; the compressors operate by on/off and step by step logic.

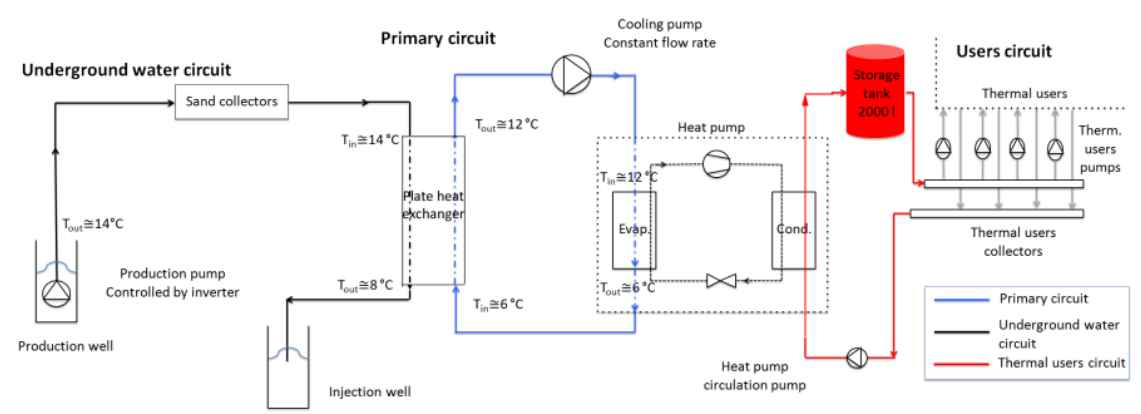

Fig. 2. Scheme of the underground water open loop heat pump plant with the three main circuits.

- users circuit: hot $\left(45^{\circ} \mathrm{C}\right)$ or cold $\left(7^{\circ} \mathrm{C}\right)$ water exiting the heat pump/chiller feeds a storage tank (2000 1) that is connected by two pumps (one backup, constant flow rate $85 \mathrm{~m}^{3} \mathrm{~h}^{-1}-, 3 \mathrm{~kW}, 8 \mathrm{~m}$ head). Finally, pumps, controlled with inverters, bring hot/cold water to each user circuit.

The showroom is set up by radiant floor as water terminal unit and displacement ventilation with very low velocity diffusers fed by two air handling units $\left(15000 \mathrm{~m}^{3} \mathrm{~h}^{-1}\right.$ each). A smaller size air handling unit $\left(1500 \mathrm{~m}^{3} \mathrm{~h}^{-1}\right)$ supplies the ventilation of the ticket 
office. The plant is connected to the local district heating network (heating backup) by a $600 \mathrm{~kW}$ (nominal thermal power) plate heat exchanger. The backup service during cooling season is made by a water/water electrical chiller (rated cooling power $330 \mathrm{~kW}$, rated electrical power $66.9 \mathrm{~kW}, \mathrm{EER}=4.95$ ). Such chiller feeds chilled water directly to users collectors and transfer the condensation heat to the primary circuit. Finally, direct expansion air conditioners (CDZ) serve two technical rooms (transformers and general switchboard and Uninterruptible Power Supply (UPS) rooms): they are cooled by the ground water circuit as well.

The first period of the monitoring activity was April-September 2014. Data analysis led to the following remarks:

- electrical energy consumption of the primary circuit pumps was extremely high (3000 $\mathrm{kWh}_{\mathrm{el}}$ per month, $44 \%$ of the total electricity consumption). This was due to the unfavorable control logic of the pumps operating $24 \mathrm{~h}$ a day even in period with very low or null cooling load. Such situation was mainly caused by the fact that the CDZ need to be cooled by underground water in every season, so CDZ are responsible for $22 \%$ of the total energy rejected into the ground water circuit in the summer period;

- the backup chiller consumed $300 \mathrm{kWh}_{\mathrm{el}}$ per month constantly only for stand-by operation;

- electrical consumption of the CDZ was quite constant in the range $1400-1700 \mathrm{kWh}_{\mathrm{el}}$ per month. It is clear that the system has an inefficient operation mode when the only cooling load is the CDZ;

- considering that the HVAC plant did not operate during the hottest period (June and July), the electrical consumption in the whole period April-September 2014 is quite high ( $35500 \mathrm{kWh}_{\mathrm{el}}$ excluding the backup chiller), especially due to the continuous operation of the primary circuit pumps even when the HVAC plant was off;

- energy performance indexes $\left(E^{2} R_{\mathrm{eq}}=\right.$ energy efficiency ratio of heat pump/chiller equipment; $\mathrm{EER}_{\mathrm{tot}}=$ energy efficiency ratio of the whole plant that is considering the auxiliary needs) resulted to be very low: $E_{E R}=3.23$ instead of a predicted value of 5; $\mathrm{EER}_{\mathrm{tot}}=1.21$ strongly penalized by low partial load operation of the plant;

- underground water consumption index $\mathrm{Q}_{\text {wat }}$ (defined as the ratio between the underground water produced and the useful cooling energy) was higher than designed: $2231 \mathrm{kWh}_{\mathrm{cool}^{-1}}{ }^{-1}$ instead of $1721 \mathrm{kWh}_{\mathrm{cool}^{-1}}$. The flow rate control capacity was not sufficient (a consumption by $1000 \mathrm{~m}^{3} \mathrm{month}^{-1}$ during the off operation periods was surveyed). The large ground water flow rate with limited $\Delta \mathrm{T}$ was due to a ground circuit pumps oversizing $\left(100 \mathrm{kPa}\right.$ was the real head at the maximum flow rate $\left(80 \mathrm{~m}^{3} \mathrm{~h}^{-1}\right)$ against $500 \mathrm{kPa}$ nominal head of the two installed pumps). This caused a very discontinuous operation of the production well pumps with poor modulation capacity and very high on-off frequency (20-30 on-off per day during very low cooling needs periods).

Because of the very poor energy performance and technical problems detected during the first period of operation, in October 2014 the local Authority approved a series of technical interventions (realized between April and August 2015):

- the extension of tube in the injection well in order to avoid excessive oxygenation and bubbling of water that could cause metals precipitation and following well obstruction (frequently occurred during 2014 and 2015);

- inserting two sensors and a balancing valve in the production well to verify the temperature and piezometric gradients and to regulate and optimize the field operation of pumps;

- modifying the operation logic of the production well pumps by increasing the operation range and making the second pump operate by the inverter as well;

- modifying the condensation heat recovery system of the ground water chiller and the backup chiller connecting directly the primary circuit to the post-heating coils;

- installing a separate dry-cooler to dissipate the CDZ condensation heat and modifying the control logic of the primary circuit pumps making them operate strictly connected to the real users cooling needs. 
The effects of the above described interventions are summarized in Fig. 3. The EER improvement was higher than $40 \%$ in summer operation. The system EER amelioration was really impressive, passing from 1.21 to 3.80 . The main contribution was the strong reduction in electrical energy consumption of the primary circuit pumps, also separating the CDZ from the ground water circuit.

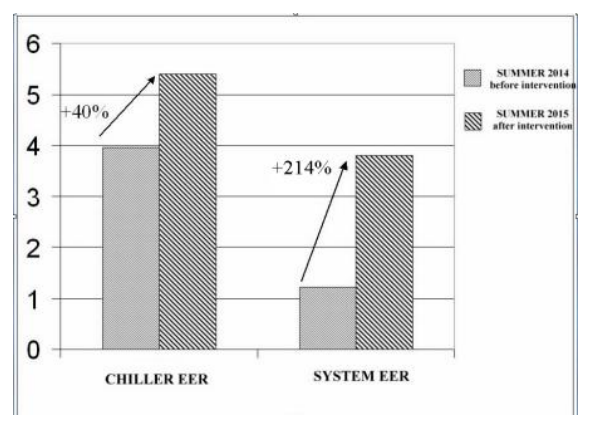

Fig. 3. Comparison of the Energy Efficiency Ratio for the two periods before and after the interventions.

\section{The third example: dual source heat pump heating of a school building}

By the town of Agordo in the geographical area of the Dolomiti mountains in a valley at $611 \mathrm{~m}$ asl, where the climate is severe during wintertime (3376 degree-day a High School Building was built up starting its operations in autumn 2009. The building has a total floor area of 5,680 $\mathrm{m}^{2}$, an outward surface of $13,608 \mathrm{~m}^{2}$ and an enclosed gross heated volume of $19,644 \mathrm{~m}^{3}$; the envelope is well insulated, the outer walls and the roof allowing an average thermal transmittance of $0.16 \mathrm{~W} /\left(\mathrm{m}^{2} \mathrm{~K}\right)$, the floor having a thermal transmittance to the ground of $0.4 \mathrm{~W} /\left(\mathrm{m}^{2} \mathrm{~K}\right)$ and the glazing system having a thermal transmittance of $1.38 \mathrm{~W} /\left(\mathrm{m}^{2} \mathrm{~K}\right)$.

The plant was designed to serve for the sole purpose of heating and ventilation, due to the severe climatic condition and the use of building, closed in summertime; moreover the demand for hot tap water is negligible and is fulfilled by means of electric water heaters. For sake of simplicity a reduced functional diagram of the plant is shown in Fig. 4 reporting only the main hydraulic streams and energy flows within the plant.

The HVAC plant is divided into the space heating section and the ventilation section. The heating section has two ammonia-water absorption heat pumps (HP3 and HP4 in Fig. 4) with geothermal exchangers in parallel $(960 \mathrm{~m}, 6 \times 160$ in a row, of vertical tube heat exchangers designed with double-U pipes with a outer diameter of $32 \mathrm{~mm}$ and a thickness of $2.9 \mathrm{~mm}$ ), producing thermal energy at $45^{\circ} \mathrm{C}$. Moreover the plant includes the setting up of $50 \mathrm{~m}^{2}$ of flat type solar heat collectors (4 arrays in parallel, each of those made of 5 modules in series), and can be operated in four different modes, the control acting on a "threshold radiation" calculated as a function of the solar collectors features and the desired outlet temperature. The ventilation section serving the AHU (Air Handling Unit) hot batteries is also made up of two ammonia-water absorption heat pumps (HP1 and HP2 in Fig. 4) with geothermal heat exchangers $(750 \mathrm{~m}, 6 \times 125 \mathrm{~m}$ in a row, of vertical tube heat exchangers). In order to serve the AHU the heat pumps produce thermal energy at $55-60^{\circ} \mathrm{C}$. The heat recuperator downstream of the AHU is a static cross flow type with an efficiency of $50 \%$. 


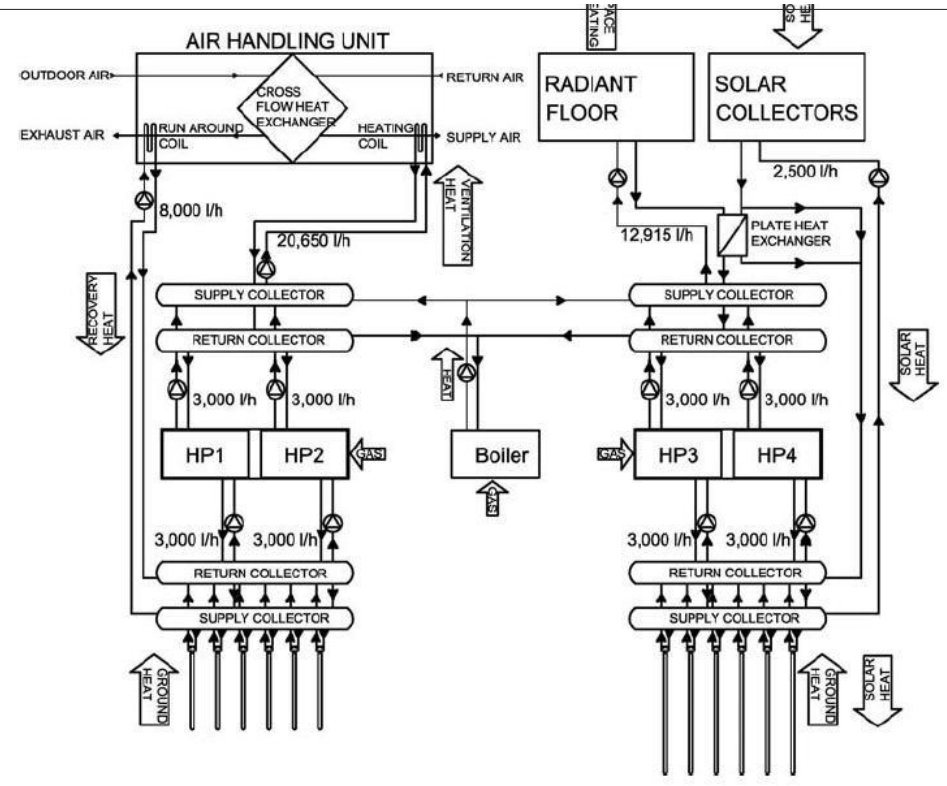

Fig. 4. Schematic of the dual source heat pump for heating a school building.

In order to increase thermal recovery still further when the external temperature exceeded $0^{\circ} \mathrm{C}$, run-around coils were installed at the outlet of two out of four, for a global volume flow of $20600 \mathrm{~m}^{3} / \mathrm{h}$ out of $25000 \mathrm{~m}^{3} / \mathrm{h}$. The run-around coils can operate on the exhaust flow of a heat exchanger, either sensible or latent; the heat recovered can be sent to the evaporator of the absorption equipment.

The monitoring of the plant was set-up with the cooperation of the building's and the plant's controller designers. The oldest data available on the PC that controls the plant, accessible from remote terminal via VPN after authentication, was from the begin of May 2012. During the period May 2012 - April 2016 the following cumulative energy flows (mass flow times the temperature difference between the inlet and the outlet, via simple thermal energy meters) were logged hourly and the results are presented in the next section on a monthly basis:

- Condenser and evaporator of each heat pump (at the collectors);

- Ground circuits, separately for ventilation and space heating;

- Primary circuit of AHU heating coils and run-around coils;

- Solar circuit;

- Primary circuit of the radiant floor.

Values of Natural Gas (NG) consumption were obtained from the natural gas bills, with all consumption being attributable to the heating/ventilation system.

As the surveys of the first two years of operation were satisfactory from the point of view of performance, no other analysis of the recorded data was operated till recently. Moreover the gas consumption changed not so much from one season to the other, supposedly according the degree-days of the various years.

The analysis of the last 4 years revealed quite a different situation. Whereas the ventilation section behaved in a similar was, this was not the case of the space heating section (fig. 5). Just in the middle of 2013 - 14 winter heat pumps did not more operate with a sudden fall in the Primary Energy Ratio (PER). Most of the energy was suddenly supplied by the boiler unlike during the previous periods. During the left part of the season the direct solar energy contribution raised system performance. However in the following winter, the solar section was completely excluded and the heat pumps occasional contribution appears as an auxiliary integration to a system where the priority is assigned to the boilers. 


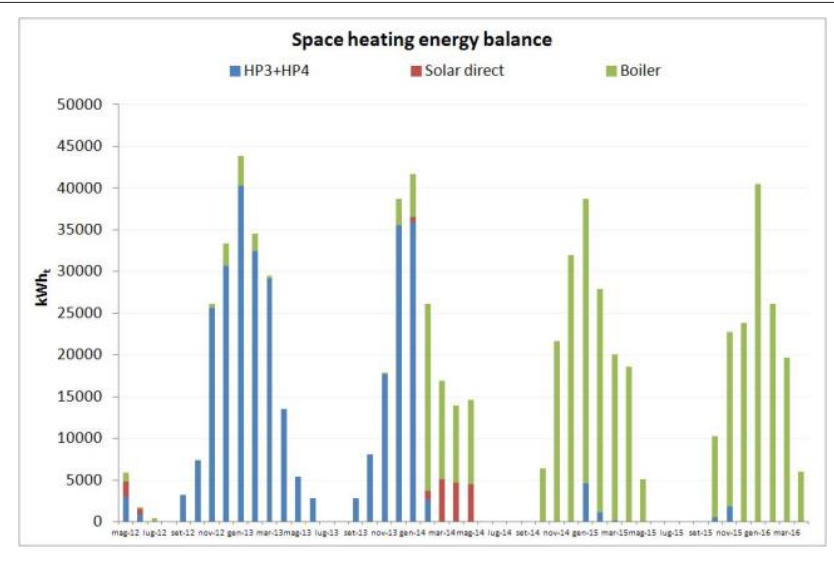

Fig. 5. Space heating energy balance of heat pumps (HP), solar direct and boilers during 4 heating seasons.

Seemingly at first the solar section was excluded from the heat pump circuit due to a failure of a solar collector. Even after fixing the solar collector problem, no circulation was reactivated between solar section and heat pump and some solar direct contribution was provided. The final choice of the management was to rely completely on boilers. The result has been a reduction of the seasonal PER to values lower than 1 . The worsening was partially hidden by some energy saving measures such as the inside temperature reduction during Christmas holidays.

\section{Conclusions}

The examples demonstrate from different points of view the paramount importance of adequate monitoring of a plant particularly for renewable energy, generally less known by technicians. According to the first example a motor driven heat pump was used as an auxiliary to a condensing boiler (just the opposite of correct operation) and due to bad temperature setting even the condensing boiler did not work in condensing mode. The second case revealed how high the electricity requested to drive pumps might be to cool even a small section of the plant. Finally the third example illustrates how the simple control on the energy bill may make acceptable the plant working, when a favourable season or energy saving measures concealed bad operation of the plant even with the exclusion of the solar section and of part of the heat pumps.

\section{References}

1. F. Busato, R.M. Lazzarin, M. Noro, Applied Thermal Engineering 31, 1648-1654 (2011)

2. M. Noro, A. D'Ascanio, R. Lazzarin, Problems and solutions of an underground water source heat pump system for a historical valuable building: an energy analysis. Proc. 12th Rehva World Congress. Aalborg (Denmark), 22-25 May, 2016

3. R, Lazzarin, M. Noro, Energy and economic analysis of an integrated multi-source heat pump system for a school building, $12^{\text {th }}$ IEA Heat Pump Conference, Rotterdam (2017) 